\title{
Coating of Cobalt Over Tungsten Carbide Powder by Wet Chemical Reduction Method
}

\author{
Hyun-Seon Hong and Jin-Ho Yoon* \\ Advanced Materials \& Processing Center, Institute for Advanced Engineering, Yongin 449-863, Korea \\ (Received February 25, 2014; Revised April 21, 2014; Accepted April 25, 2014)
}

\begin{abstract}
Cobalt coated tungsten carbide-cobalt composite powder has been prepared through wet chemical reduction method. The cobalt sulfate solution was converted to the cobalt chloride then the cobalt hydroxide. The tungsten carbide powders were added in to the cobalt hydroxide, the cobalt hydroxide was reduced and coated over tungsten carbide powder using hypo-phosphorous acid. Both the cobalt and the tungsten carbide phase peaks were evident in the tungsten carbide-cobalt composite powder by X-ray diffraction. The average particle size measured via scanning electron microscope, particle size analysis was around $380 \mathrm{~nm}$ and the thickness of coated cobalt was determined to be $30 \sim 40 \mathrm{~nm}$ by transmission electron microscopy.
\end{abstract}

Keywords: Submicron composite, WC-Co composite powder, Wet chemical reduction method, Zeta potential, Coating thickness

\section{Introduction}

Development of various tough materials has increased need for the material machining technique, accordingly, demands for cutting tools such as cemented carbide tools are also rapidly increasing. A cemented carbide tool has excellent hardness and deflective strength at high temperature. Thus, the cemented carbide tools (like tungsten carbide-cobalt (WC-Co) composite) are widely used in the industries for precise machining due to its superior wear resistance, and machinability.

The mechanical characteristics of the cemented carbide material mostly depend on the process like sintering and characteristics of raw materials like shape, size, distribution and thickness of cobalt $(\mathrm{Co})$ coating of tungsten carbide-cobalt (WC-Co) composite. Though the tungsten carbide (WC) raw material is being used in industry, the WC-Co composite has significantly better mechanical properties over WC. In the WC-Co composite size and thickness of the Co coating plays a vital role. Therefore, the technique, which produces nano-sized Co, plays an essential role in improving the properties of the cemented carbide tools. Also, the Co can be used in various forms in the manufacturing process of the $\mathrm{WC}$ tools due to its superior moldability, particle size, shape, and chemical purity. The Co has been the most commonly used material because it can be effectively compacted up to a theoretical density by hot pressing at relatively low temperature and pressure conditions.

To improve the properties of the WC tools, synthesis of WC-Co composite by various route such as hydrothermal, electro-thermal explosion directional spraying, spark plasma sintering, liquid phase sintering, hot press sintering has been reported [1-6]. In our process very simple and easier process been developed for coating of 30-40 $\mathrm{nm}$ Co, which further can be scaled up for commercial production.

\section{Experiment}

The experiment was performed to the following process to the synthesis of WC-Co submicron composite similar to our process report elsewhere [7]. Fig. 1 depicts the process flow sheet for synthesis of WC-Co composite. A

*Corresponding Author : Jin-Ho Yoon, TEL: +82-31-330-7481, FAX: +82-31-330-7113, E-mail: yjh6373@iae.re.kr 


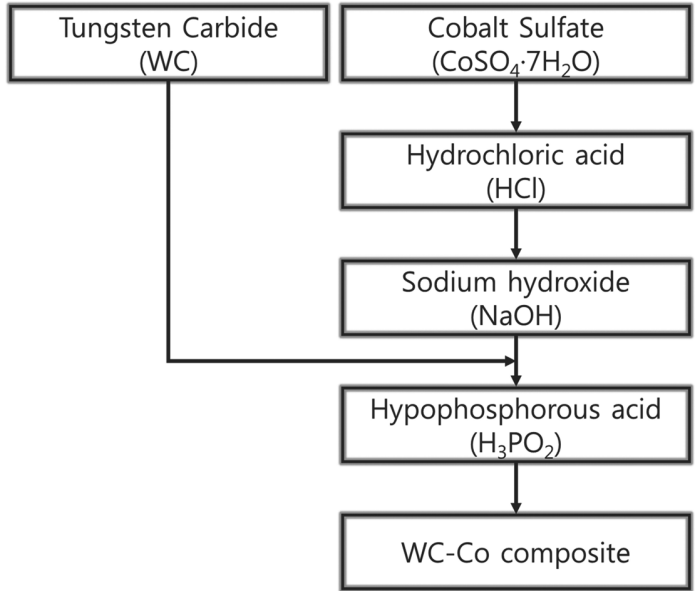

Fig. 1. Process flow sheet for synthesis of WC-Co composite.

cobalt sulfate $\left(\mathrm{CoSO}_{4} \cdot 7 \mathrm{H}_{2} \mathrm{O}\right)$ solution was dissolved in deionized (DI) water in a reactor, and the cobalt sulfate solution was substituted with cobalt chloride $\left(\mathrm{CoCl}_{2}\right)$ adding 35\% hydrochloric acid $(\mathrm{HCl})$ under agitation for 10 min. The $\mathrm{CoCl}_{2}$ was again substituted as cobalt hydroxide $\left(\mathrm{Co}(\mathrm{OH})_{2}\right)$ by sodium hydroxide $(\mathrm{NaOH})$. The WC powder was added and allowed to diffuse so that the $\mathrm{Co}(\mathrm{OH})_{2}$ can evenly adhere to the surface of WC. Finally the reductant hypophosphoric acid $\left(\mathrm{H}_{3} \mathrm{PO}_{2}\right)$ was added to reduce the $\mathrm{Co}(\mathrm{OH})_{2}$ to the Co over the WC surface. The synthesized WC-Co composite powder was washed several times using DI water and ethanol, and was finally dried using a vacuum desiccator. The synthesized WCCo composite powder was characterized by X-ray diffraction (XRD, ATX-G, Rigaku), scanning electron microscope (SEM, Nova Nano 200, FEI) and by transmission electron microscopy (TEM, JEM 4000FX, JEOL). The particle size and zeta potential of the WC-Co were analyzed through zeta potential and particle size analyzer (ELSZ-2, Photal).

\section{Results and Discussion}

The crystal structure of the WC-Co composite powder was analyzed using XRD, and Fig. 2 shows the result. As shown in XRD, the primary (main) peaks for the WC-Co composite powder, i.e. (001), (100), and (101), (JDPDS 51-0939), and peaks (100), (101) and (002) for Co (JCPDS 05-0727) were identified, when the scanned angle $2 \theta \mathrm{s}$ were in between $40-48^{\circ}$ radian. The peaks (101) for WC and Co were superimposed, hardly can be observed

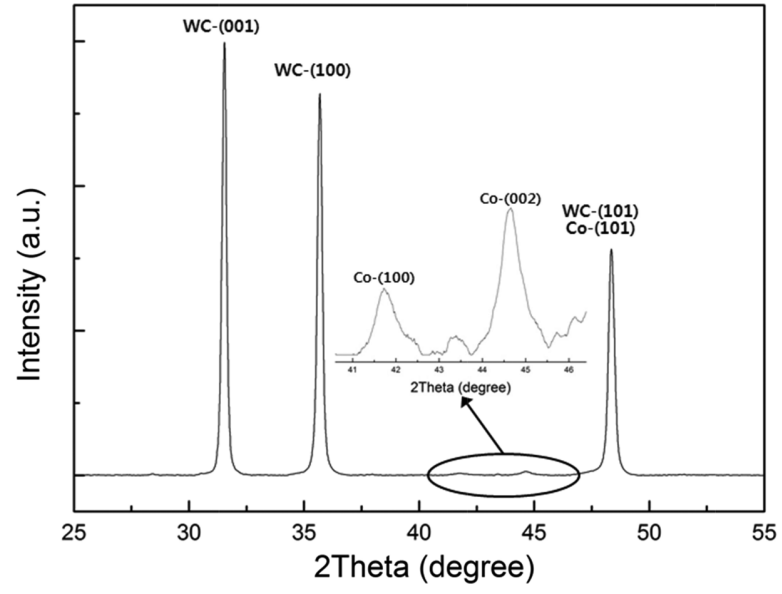

Fig. 2. The XRD of the WC-Co composite powder.

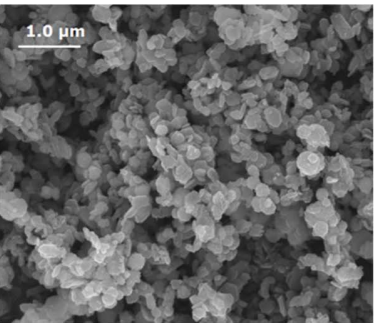

(a)

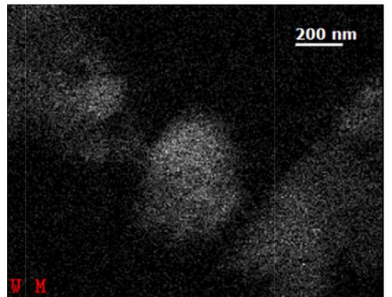

(c)

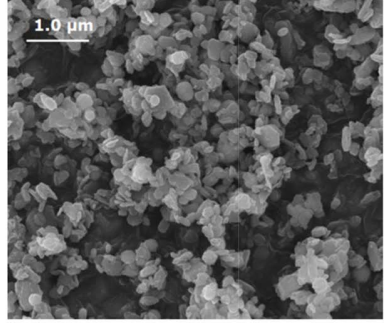

(b)

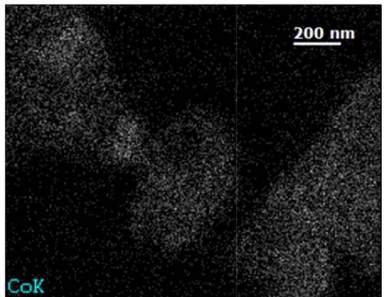

(d)

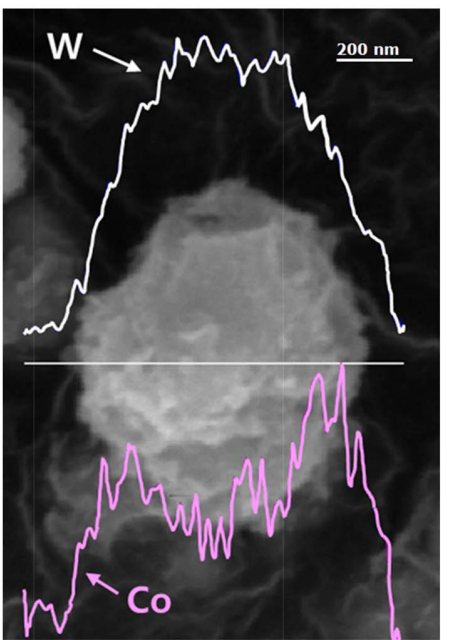

(e)

Fig. 3. The SEM of the WC-Co composite powder. (a) the pure WC, (b) WC-Co, EDS analysis of (c) W, EDS analysis of (d) Co, and (e) Line scanning analysis.

directly.

Fig. 3(a) and (b), the SEM show the surfaces of WC 


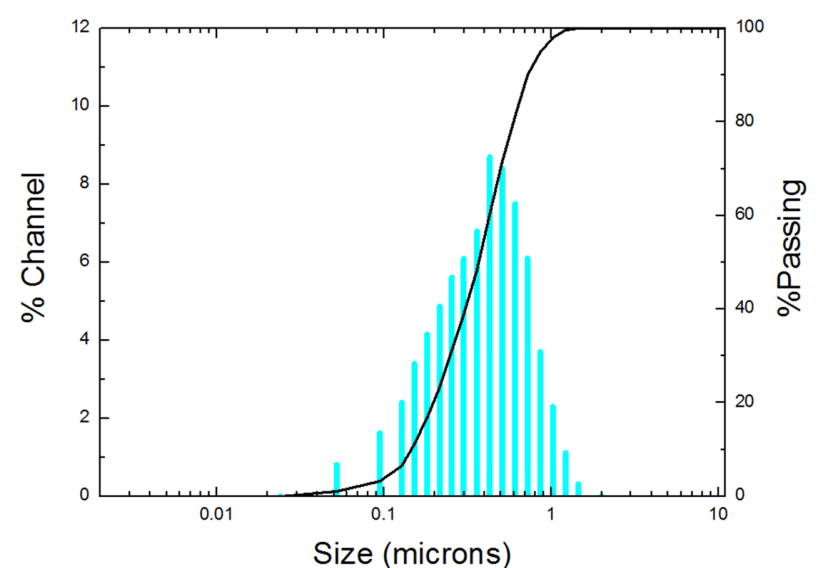

Fig. 4. Distribution of WC-Co composite powder.

and the WC-Co composite powder observed. The observed particle size was about 100-700 nm for WC and the WCCo composite powder, respectively. The distribution of each element was examined via energy-dispersive spectrometry (EDS) to identify the elements of the WC-Co composite powder. Fig. 3(c) and (d) show the EDS mapping of the WC-Co composite powder. Both tungsten (W), the element of WC, and Co are evenly distributed, but distribution for $\mathrm{W}$ is more intense than Co. Fig. 3(e) shows the element distribution of the WC-Co composite powder observed via line scanning. The $\mathrm{W}$ was found to be distributed relatively near the central region, and the Co was found to be distributed relatively near the edge region, reasonably concluded that that the surface of WC is coated with Co.

Fig. 4 shows the particle distribution of the WC-Co composite powder, was examined by PSA. The average particle size was $381 \mathrm{~nm}$, and $\mathrm{D}_{10}$ and $\mathrm{D}_{90}$ were 149 and $720 \mathrm{~nm}$, respectively. Thus, the dispersibility of WC-Co is 4.8. The particle distribution of the composite powder is consistent as observed in SEM.

To figure out the coating condition of the WC-Co composite powder, the cross-section of the WC-Co composite powder was cut using FIB, and the distribution of Co was examined via TEM. As shown in Fig. 5(a), the surface of WC is uniformly coated with the Co, and the thickness of the Co coating is $30-40 \mathrm{~nm}$. The inter-planar spacing of each elements of WC-Co was calculated via FFT, and Fig. 5(b) shows the result. The center and edge regions of the WC-Co composite powder were arbitrarily established, and the SEAD pattern was presented. Each interplanar spacing was measured using the calculated result.

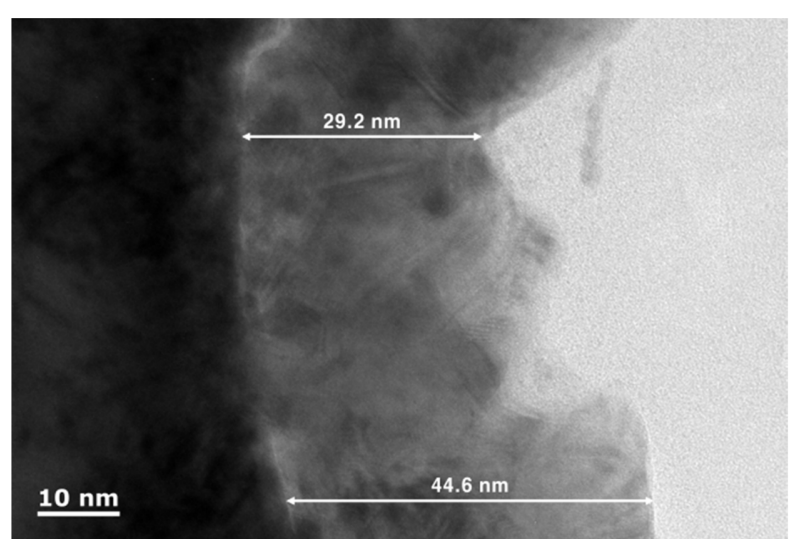

(a)

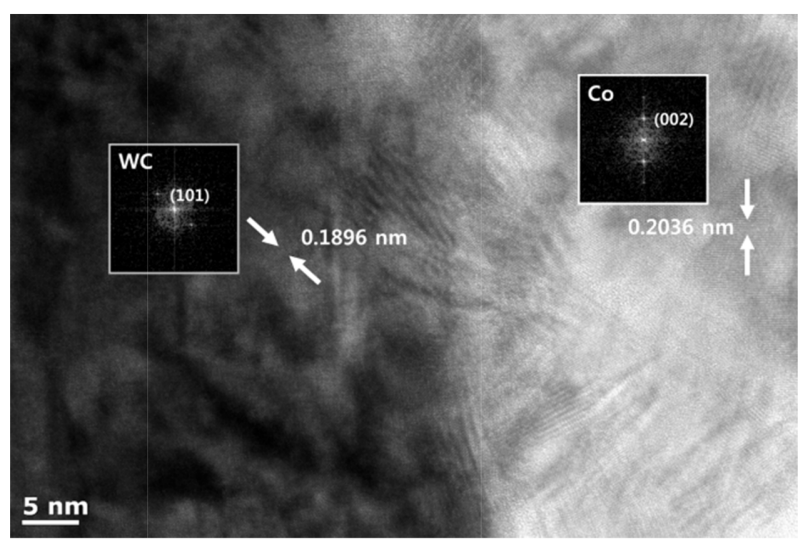

(b)

Fig. 5. TEM analyzed result of the WC-Co composite powder, (a) the cross-section of the WC-Co composite powder, (b) WCCo composite powder and interplanar distance and FFT analysis.

In the WC area, which is the central region, a $0.1896 \mathrm{~nm}$ inter-planar spacing was calculated, which is consistent with (101) superimposed peak of the XRD analysis presented Fig. 2. In the Co area, which is the edge region, a 0.2036 $\mathrm{nm}$ inter-planar spacing was calculated, which is also consistent for the (002) peak of Co. In the WC-Co composite powder, the boundary of WC (center region) is uniformly coated with Co, with a thickness of 30-40 nm.

In general, the redox reaction of metal spontaneously feasible when the total electrochemical potential $\left(\Delta E_{0}\right)$ has a positive value, and the reduction-oxidation half shell reactions for $\mathrm{Co}(\mathrm{OH})_{2}$ and $\mathrm{H}_{3} \mathrm{PO}_{3}$, respectively in basic solution can be expressed as follow:

$$
\begin{aligned}
& \mathrm{Co}(\mathrm{OH})_{2}+2^{\mathrm{e}-} \rightarrow \mathrm{Co}+2 \mathrm{OH}^{-}\left(\mathrm{E}_{0}=-0.730 \mathrm{~V}\right) \\
& \mathrm{H}_{3} \mathrm{PO}_{3}+2 \mathrm{H}^{+}+2 \mathrm{e} \rightarrow \mathrm{H}_{3} \mathrm{PO}_{2}+\mathrm{H}_{2} \mathrm{O}\left(\mathrm{E}_{0}=-0.499 \mathrm{~V}\right)
\end{aligned}
$$

where $E_{0}$ is the standard electrode potential. If the $E_{0}$ of the reduction reaction is lower than the $E_{0}$ of oxidation 


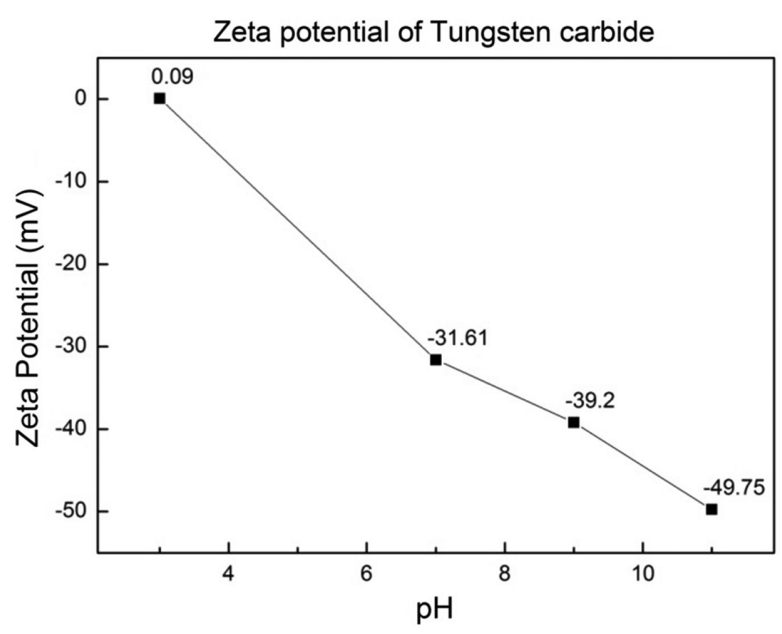

Fig. 6. The zeta potential of WC powder at various pH.

reaction, the $\Delta E$ of oxidation-reduction reaction has a positive value, and a spontaneous reaction occurs. Therefore, $\mathrm{Co}(\mathrm{OH})_{2}$ is spontaneously reduced to nano cobalt powder by reducing the agent, $\mathrm{H}_{3} \mathrm{PO}_{3}$, at room temperature while the reducing agent, $\mathrm{H}_{3} \mathrm{PO}_{3}$ experiences the oxidation reaction. The reaction of $\mathrm{Co}(\mathrm{OH})_{2}$ and $\mathrm{H}_{3} \mathrm{PO}_{3}$ can be expressed as the following reaction formula:

$$
2 \mathrm{Co}(\mathrm{OH})_{2}+\mathrm{H}_{3} \mathrm{PO}_{2} \rightarrow 2 \mathrm{Co}+\mathrm{H}_{3} \mathrm{PO}_{4}+2 \mathrm{H}_{2} \mathrm{O} .
$$

To figure out whether the reduction reaction of Co is feasible at the surface of WC, the zeta potential of WC was measured depending on the $\mathrm{pH}$, and Fig. 6 shows the result. At $\mathrm{pH} 3$, which is an acidic condition, the zeta potential was $0.09 \mathrm{mV}$, but as the $\mathrm{pH}$ was increased to 7,9 , and 11 , the zeta potential was decreased to $-31.61,-39.2$, and -49.75 $\mathrm{mV}$. It is enough energy for $\mathrm{Co}^{2+}$, which is the cation of $\mathrm{Co}(\mathrm{OH})_{2}$, to adhere to the surface of WC, and through this result, Co was found to be uniformly formed on the surface of WC. This is consistent with the fact that it is not that Co exists as powder by independent reduction.

\section{Conclusions}

The WC-Co composite powder was successfully synthe- sized at room temperature by wet chemical reduction method. The cobalt sulfate solution was converted to the cobalt chloride then the cobalt hydroxide. The tungsten carbide powders were added in to the cobalt hydroxide, the cobalt hydroxide was reduced and coated over tungsten carbide powder using hypophosphoric acid. The WC-Co composite powder was nanocrystalline materials and the average particle size was around $380 \mathrm{~nm}$. The surface of WC uniformly coated with the Co, and the thickness was 30 40 $\mathrm{nm}$. The zeta potential showed $-49.75 \mathrm{mV}$, when the $\mathrm{pH}$ is 11 . It is enough energy for $\mathrm{Co}^{2+}$ to adhere to the surface of WC, Co was found to be uniformly formed on the surface of WC. The synthesized WC-Co composite powder is expected to improve the characteristic of the cemented-carbide tool.

\section{Acknowledgements}

This work was supported by a grant from the Fundamental R\&D Program for Core Technology of Materials (10037201) funded by the Ministry of Trade, Industry and Energy, Republic of Korea.

\section{References}

[1] G. Jin, B. Xu, H. Wang, Q. Li and S. Wei: Mater Lett., 61 (2007) 2454.

[2] J. Sun, F. Zhang and J. Shen: Mater Lett., 57 (2003) 3140.

[3] O. O. Eso, P. Fan and Z. Z. Fang: Int. J. Refract Met. Hard Mater., 26 (2008) 91.

[4] H. Lin, B. Tao, Q. Li and Y. Li: Mater Res. Bull., 47 (2012) 3283.

[5] O. Eso, Z. Fang and A. Griffo: Int. J. Refract Met. Hard Mater., 23 (2005) 233.

[6] C Jia, H. Tang, X. Mei, F. Yin and X. Qu: Mater Lett., 59 (2005) 2566.

[7] H. S. Hong, Y. D. Ko, L. S. Kang, G. H. Kim and H. C. Jung: J. Kor. Powd. Met. Inst., 18 (2011) 244 (Korean). 